\title{
An in-plant milk-run design method for improving surface occupation and optimizing mizusumashi work time
}

\author{
Francisco Gil Vilda ${ }^{\mathrm{a}}$, José A. Yagüe-Fabra $(2)^{\mathrm{b}, *}$, Albert Sunyer Torrents ${ }^{\mathrm{c}}$ \\ a LEANBOX SL, Distrito 22@. C/ Juan de Austria 126, Barcelona 08018, Spain \\ ${ }^{\mathrm{b}}$ I3A- Universidad de Zaragoza, C/ María de Luna, 3, Zaragoza 50018, Spain \\ ' Universitat Politècnica de Catalunya, C/ Colom, 11, Terrassa, Barcelona 08222, Spain
}

\section{A R T I C L E I N F O}

\section{Article history:}

Available online xxx

\section{Keywords:}

Logistics

Productivity

In-plant milk-run

\begin{abstract}
A B S T R A C T
Product customization is becoming a competitiveness factor in most markets. It implies manufacturing small and varied batches in mixed-product assembly lines and frequently supplying parts to production lines in small quantities with high efficiency. The in-plant milk-run is a specific tool used in this context. This paper proposes an industry-validated design method for human-driven milk-runs, based on improving surface productivity. A mathematical model is defined for relating mizusumashi work time to the milk-run period and finding its minimum value. This research is particularly useful in factories with high cost per $\mathrm{m}^{2}$ supplying high-volume parts.
\end{abstract}

C 2020 CIRP. Published by Elsevier Ltd. All rights reserved.

\section{Introduction}

The general trend in highly competitive markets is to increase product variety to fulfil diverse customers' needs. This is one of the reasons why manufacturers currently receive more fragmented demand. Thus, designing a flexible production system able to work efficiently with small and varied batches constitutes a key competitive factor.

Lean Production Systems are well adapted to this context. They are based on the Toyota Production System, developed as a 'multikind, small-quantity production system' based on 'the absolute elimination of waste' [1]. 'Transporting' and 'Motion' are two of the 7 wastes, critical to logistic optimization.

Baudin [2] introduced the concept of in-plant Lean Logistics to efficiently supply parts to mixed-product assembly lines that produce small batches. The in-plant milk run is one of the tools that serve this purpose. It consists of a transportation system that delivers materials from a storage area to several points of use (POUs) on defined routes in short and fixed periods. During this period, the material handler (mizusumashi) picks up containers at the storage areas; follows a predetermined standard route using multi-coach trains; delivers them to various POUs; and on the return trip bring empty containers back to the source [3]. The milk run has been reported to be suitable for handling materials in repetitive pull-flow production for high product mix $[4,5]$.

\section{Literature review}

Toyota reported that mizusumashi was first introduced in 1955 and evolved in 1977 to a multi-stop delivery system [6]. In 1982, Schonberger [7] used for the first time the term "water beetle" (English translation for mizusumashi) referring to the in-bound

\footnotetext{
* Corresponding author.

E-mail address: jyague@unizar.es (J.A. Yagüe-Fabra).
}

logistics of making numerous trips to move parts in very small quantities. Recent papers apply the term mizusumashi to the handler who operates the milk run: A handler who supplies only the necessary items in the necessary quantities at the necessary time [8]. This paper uses the term mizusumashi for the handler tasks, and milk run for the in-plant transportation system.

Nomura and Takakuwa [9] developed a mathematical milk-run model for determining the minimal number of containers necessary for supplying parts to assembly lines considering work time and inventory levels. Further mathematical models can be found to address the problem of how to allocate containers to tours [10], to design and manage the milk-run and inventory levels driven by kanban systems [11], to schedule and load tugger trains [12] and to examine mizusumashi's utilization and impact on the manufacturing system [13].

A review and categorization of in-plant milk runs reported that material handling occupies 55\% of a factory's surface [14]. Recent research on milk-run design, such as the Vehicle Routing Problem (VRP), has focused mainly on minimizing the total distance travelled or minimizing the number of vehicles applied $[15,16]$ but less attention has been paid to milk-run design for surface reduction and handling productivity [17].

This study is based on mathematical modelling and actual practice for milk-run design, focusing on surface and labour productivity, which is supplemental to VRP perspective. It proposes an inplant milk-run design method for reducing surface requirements as a main goal and, under these boundary conditions, minimizing mizusumashi work time.

\section{In-plant milk-run design method for surface reduction}

This analysis uses the following terminology: an in-plant milk run takes place during working time $S$ and delivers $n$ different parts 
Table 1

Notation and empirical values collected in a case study.

\begin{tabular}{|c|c|c|c|}
\hline & Description & Notation & Case study values \\
\hline \multirow[t]{7}{*}{ Milk-run loop } & Supply time (working time) & $S$ & $480 \mathrm{~min}$ (1 shift) \\
\hline & Frequency (loops per $S$ ) & $F$ & - \\
\hline & Milk-run period (S/F) & $P$ & - \\
\hline & $\begin{array}{l}\text { Transportation time for one } \\
\text { loop }\end{array}$ & $T_{t}$ & $4 \mathrm{~min}$ \\
\hline & Number of points of use (POU) & $m$ & 12 POUs \\
\hline & Parts to supply & $n$ & $2 \cdot m$ \\
\hline & Number of coaches & $N$ & - \\
\hline POU & POU consumption cycle time & $C_{t}$ & $40 \mathrm{~s}$ \\
\hline \multirow[t]{4}{*}{ Coach } & Coach length & $L_{v}$ & $120 \mathrm{~cm}$ \\
\hline & Coach width & $W_{v}$ & $60 \mathrm{~cm}$ \\
\hline & Coach height & $H_{v}$ & $100 \mathrm{~cm}$ \\
\hline & $\begin{array}{l}\text { Coach walking length }=L_{v}+W_{v} / \\
2\end{array}$ & $L$ & $150 \mathrm{~cm}$ \\
\hline \multirow[t]{4}{*}{ Container } & Container length & $L_{c}$ & $60 \mathrm{~cm}$ \\
\hline & Container width & $W_{c}$ & $40 \mathrm{~cm}$ \\
\hline & Container height & $H_{c}$ & $25 \mathrm{~cm}$ \\
\hline & Units per container & $u$ & 8 parts \\
\hline \multirow[t]{3}{*}{ Motion } & $\begin{array}{l}\text { Time to manipulate one } \\
\text { container }\end{array}$ & $T_{h}$ & $2 \mathrm{~s}$ \\
\hline & $\begin{array}{l}\text { Time to walk a step by } \\
\text { mizusumashi }\end{array}$ & $T_{w}$ & $0.8 \mathrm{~s} / \mathrm{m}$ \\
\hline & Walking distance per loop & $D$ & - \\
\hline \multirow[t]{4}{*}{ Ratios } & Container volume & $L_{c} \cdot W_{c} \cdot H_{c}$ & $0.06 \mathrm{~m}^{3}$ \\
\hline & Coach Volume & $L_{v} \cdot W_{v} \cdot H_{v}$ & $0.72 \mathrm{~m}^{3}$ \\
\hline & $\begin{array}{l}\text { Number of containers per } \\
\text { coach }\end{array}$ & $M$ & 12 \\
\hline & $\alpha=n /(M \cdot u)$ & $\alpha$ & 0.21 \\
\hline
\end{tabular}

within a replenishment period $P$ to $m$ POUs that consume the parts at a $C_{t}$ cycle time (notation in Table 1 ).

\subsection{Surface reduction factors}

Surface plant consumption due to internal logistics processes are related, at least, with two main factors:

1. Aisles surface to ensure space is enough for material transportation and ergonomic handling (Fig. 1.)

2. Surface used by full and empty containers laid at the POUs.

Milk-run design method influences both factors as follows:

1. Aisles surface occupied is defined by aisle length and width. Minimum width requirements are set by the coach width plus the minimum distance to ensure a safe handling from the coach to the POU (Fig. 1a).

2. Surface occupied by containers is proportional to the number of containers required by the POU for a non-stop production. According to [9], the number of containers $\left(N_{c}\right)$ at a POU that are replenished every $P$ time by a mizusumashi can be calculated by Eq. (1):

$N c=\frac{P+L T}{C_{t} \cdot u}$

Where $L T$ is the time since the mizusumashi sees the container needs to the moment he comes back and supplies the POU; $u$ is the number of parts per container and $C_{t}$ is the consumption cycle time at the POU.

There are two ways to reduce $N_{c}$ and, therefore, the surface needed at the POU:

- Make $L T \rightarrow 0$. The maximum number of containers consumed by a POU during $P$ is $\frac{P}{C_{t} \cdot u}$. If coach preloads this number of containers, supplies can be delivered immediately, and $L T$ becomes negligible. This approach is coined 'preloading method'.

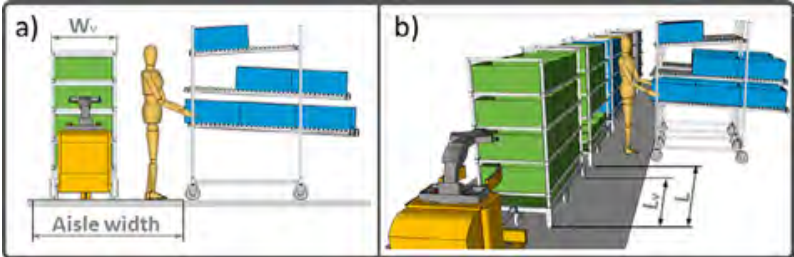

Fig. 1. Mizusumashi supplying a POU. a) Front view; b) 3D view.
- Reduce $P$ as much as possible. This is particularly relevant because, accordingly to [17], production cells surface has a quadratic relationship with $P$. Nevertheless, $P$ reduction has some limits: the shorter the $P$, the more trips from storage to POUs are needed, so more driving time is added to mizusumashi workload.

Therefore, three rules can be issued for a design method oriented towards reducing surface occupation:

1. Minimizing coach width $\left(W_{v}\right)$ to minimize aisle surfaces.

2. Using the 'preloading method' to minimize mizusumashi's lead time and the number of containers at POUs (Eq. (1)).

3. Shortening the replenishment period $(P)$ to reduce the production line surface due to containers at its POUs [17].

The next step in this study is to model the mizusumashis work time in order to calculate $P$ for a minimum work time, always within the boundary conditions established by the three mentioned rules.

\subsection{Milk-run period $(P)$ for minimum mizusumashi work time}

Even though a short $P$ is preferred for minimizing the production line surface, $P$ has a direct impact on the mizusumashi's workload $(W L)$ during the supply time $(S)$, which is calculated as the work time in Eq. (2):

$$
\begin{aligned}
W L & =\text { driving time }+ \text { handling time }+ \text { walking time } \\
& =W L_{d}+W L_{h}+W L_{w}
\end{aligned}
$$

Eq. (2) components are studied below aiming to minimize the work time function. The notation used is shown in Table 1:

Driving time $\left(W L_{d}\right)$ during the supply time $(S)$ is calculated by Eq. (3):

$W L_{d}=$ number of loops $\cdot T_{t}=\frac{S}{P} \cdot T_{t}=F \cdot T_{t}=f\left(\frac{1}{P}\right)$

Therefore, driving time can be expressed as a reverse function of the milk-run period $(P)$.

Handling time $\left(W L_{h}\right)$ for loading and unloading containers during the supply time $(S)$ is calculated by Eq. (4):

$W L_{h}=\sum_{i=1}^{n}\left(4 \cdot \frac{S}{C_{t i} u_{i}} \cdot T_{h i}\right)$

Where $i$ is the type of part to be supplied and $u_{i}$ is the number of units of part $i$ inside its container.

Note that every container is handled 4 times: 2 times (full, empty) at POU and 2 times (empty, full) at the storage area.

Thus, once the workstation cycle time $\left(C t_{i}\right)$ is defined for each part and the container geometry is defined, handling time during $S$ time becomes a constant that remains independent of the milk-run period $(P)$.

Walking time $\left(W L_{w}\right)$ up and down the train during the supply time $(S)$ is proportional (Fig. 2) to the number of coaches $(N)$. Using the 'preloading method', defined in Section 3.1, $N$ can be calculated solving the Bin Packing Problem (BPP) $[18,19]$ or by Eq. (5) if standard containers fit perfectly in the coach.

$N=\frac{\text { Volume of preloaded containers }}{\text { Volume of }}$

$\mathrm{N}=\frac{\text { Volume of the standard coach }}{\text { Volut }}$

$=\frac{\sum_{i=1}^{n}\left[\left(L_{c i} \cdot W_{c i} \cdot H_{c i}\right) \cdot \frac{P}{C_{t i} \cdot u_{i}}\right]}{L_{v} \cdot W_{v} \cdot H_{v}}$

Thus, walking time is proportional to the milk-run period $(P)$ and, therefore, a function of it.

In conclusion, the total mizusumashi work time $(W L)$ during the supply time $(S)$ defined in Eq. (2) can be simplified and expressed in terms of the milk-run period $(P)$, as in Eq. (6):

$W L(P)=f_{1}\left(\frac{1}{P}\right)+$ Constant $+f_{2}(P)$ 


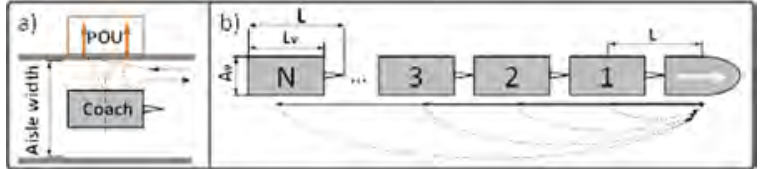

Fig. 2. a) Dimensions of the milk-run coach and POU; b) Mizusumashi walking schema up and down the train in every loop.

Once having established a mathematical relationship between $W L$ and $P$, a question arises: Is there an optimum milk-run period $(P)$ that minimizes $W L$ ? To answer this question, the model must include walking time $\left(W L_{w}\right)$, which is the third term in Eq. (6), and therefore walking distance.

\subsection{Modelling the stopping strategy and walking time}

This key point has been developed based on directly observing industrial milk-run systems in different plants and interviewing experienced mizusumashis. As a result, the following restrictions have been introduced:

- The coach should stop in front of the POU in order to optimize handling motion. POUs width should be as close as possible to coach length (Fig. 1b, 2a).

- From an ergonomic point of view, the mizusumashi should walk the minimum distance while carrying full containers. Thus, he should go to the head of the train and move it forward to place every coach in front of its POU.

Under these conditions, the mizusumashi walks as shown in Fig. 2b, twice every loop (once in the production area to supply the POUs, and another time while in the storage area to load the train). Therefore, this walking distance per loop $(D)$ can be expressed as in Eq. (7). Bear in mind that $\mathrm{D}$ is an arithmetic progression.

$D=2 \cdot(2 L+4 L+6 L+\cdots+2 \mathrm{NL})=4 \cdot L \sum_{i=1}^{N} i=4 \cdot L \cdot N \cdot \frac{1+N}{2}$

Notice that this approach is valid if every coach loads parts for a single POU, which is realistic when $N \geq m$. This is also the case when supplying large parts (focus of this research).

In such a situation, walking time $\left(W L_{w}\right)$ during the supply time $(S)$ can be formulated as in Eq. (8).

$W L_{w}=\frac{S}{P} \cdot D \cdot T_{w}=2 \cdot \frac{S}{P} \cdot L \cdot N \cdot(N+1) \cdot T_{w}$

If $N<m$, every coach must stop at several POUs, and the mizusumashi must walk the distance $D$ several times. $m / N$ could be considered a correction factor in this case.

\subsection{Final formulation for mizusumashi work time (WL)}

In summary, mizusumashi work time (WL) can be expressed, according to Eq. (2) and Eq. (6), as the sum of: the driving time $\left(W L_{d}\right)$, which is expressed in Eq. (3); the handling time $\left(W L_{h}\right)$, shown in Eq. (4); and the walking time $\left(W L_{w}\right)$ that is indicated in Eq. (8). The final expression is shown in Eq. (9):

$W L=\frac{S}{P} T_{t}+\sum_{i=1}^{n}\left(4 \cdot \frac{S}{C_{t i}} \cdot \frac{1}{u_{i}} \cdot T_{h i}\right)+2 \cdot \frac{S}{P} \cdot L \cdot T_{w} \cdot N \cdot(N+1)$

where $N$ is calculated according to Eq. (5). As mentioned above, this is valid when supplying large parts.

\section{Discussion}

As shown in Eq. (9), the mizusumashi's workload (WL) is a discrete function because both, the number of containers and the number of coaches, are natural numbers. Therefore, its minimum cannot be calculated by derivation, but it can be obtained by graphical analysis. This is done in Section 4.2.
However, expressing WL as a continuous function could help us to understand the relationships between the different variables, especially between $P$ and WL. An approach to that is described in Section 4.1.

\subsection{WL continuous function approach}

In order to simplify the formulation for the abovementioned continuous function, some adjustments are made: First, we consider standard containers with the same dimensions and the same parts inside; second, the workstation cycle time $\left(C_{t}\right)$ will be the same at every POU.

With these assumptions, we can simplify Eq. (5), which calculates the number of coaches $(N)$. This is shown in Eq. (10):

$$
\begin{aligned}
N & =\frac{\sum_{i=1}^{n}\left[\left(L_{c i} \cdot A_{c i} \cdot H_{c i}\right) \cdot \frac{P}{C_{t i} \cdot u_{i}}\right]}{L_{v} \cdot A_{v} \cdot H_{v}}=\frac{n \cdot P \cdot\left(L_{c i} \cdot A_{c i} \cdot H_{c i}\right)}{L_{v} \cdot A_{v} \cdot H_{v} \cdot T_{c} \cdot u}=\frac{n \cdot P}{M \cdot C_{t} \cdot u} \\
& =\alpha \cdot \frac{P}{C_{t}}
\end{aligned}
$$

where $M$ is the number of containers per coach and the ratio $\alpha=n /$ $(M \cdot u), n$ is the number of parts to supply, and $u$ is the number of parts per container.

With $N$ calculated as in Eq. (10), the walking time $\left(W L_{w}\right)$ could be calculated by Eq. (8). The total mizusumashi work time (WL) defined by Eq. (9) can be expressed as in Eq. (11).

$W L(P)=\frac{S}{P} \cdot T_{t}+$ Constant $+2 \cdot \frac{S}{P} \cdot L \cdot \alpha \cdot \frac{P}{C_{t c}} \cdot\left(\alpha \cdot \frac{P}{C_{t}}+1\right) \cdot T_{W}$

This expression allows minimizing the mizusumashi work time during the milk-run period $(P)$, doing so by derivation, i.e., making $\mathrm{d} W L / \mathrm{d} P=0$, as shown in Eq. (12).

$\frac{d W L}{d P}=-\frac{S}{P^{2}} \cdot T_{t}+\frac{2 \cdot S \cdot L \cdot \alpha^{2} \cdot T_{w}}{C_{t}^{2}}=0$

By clearing $P$ from Eq. (12), Eq. (13) is obtained. This can then be used to calculate the optimum milk-run period $(P)$ for a minimum mizusumashi work time under the assumptions mentioned at the beginning of this subsection.

$P=\frac{C_{t} \cdot M \cdot u}{n} \sqrt{\frac{T_{t}}{2 \cdot L \cdot T_{w}}}$

\subsection{Graphical analysis for calculating optimum $P$}

As mentioned above, WL is a discrete function and therefore we can use graphical analysis to obtain general results without applying simplifications.

A case analysis has been developed based in a real process from a production plant located in Zaragoza (Spain). The studied product is a car component built by 4 large plastic parts, moulded and later assembled in U-Shaped cells in the same plant. An internal milk-run transfers these parts from the moulding supermarket (Fig. 3a) to cells' POUs (Fig. 3b). Two parts are supplied to each POU $(n=2 \mathrm{~m})$. Empirical values collected from the company are shown in Table 1.

The main goal of this analysis is to obtain the optimal milkrun period $(P)$ that minimizes the mizusumashi's total work time $(W L)$. To that end, Eqs. (3), (4) and (8) are applied for calculating the three components of $W L\left(W L_{d}, W L_{h}\right.$ and $W L_{w}$, respectively) (see Fig. 4), and Eq. (9) is then used to calculate total WL. In Fig. 5, WL is calculated for different numbers of POUs $(m)$ in order to study their relationships.

When $N<m$, the correction factor defined in Section 3.3 is applied to Eq. (9) in order to obtain more realistic results.

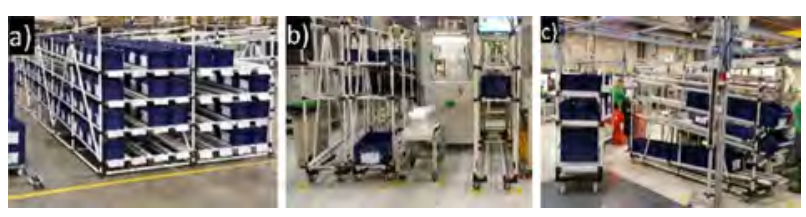

Fig. 3. a) Supermarket; b) Typical POU; c) Milk-run facing a POU. 


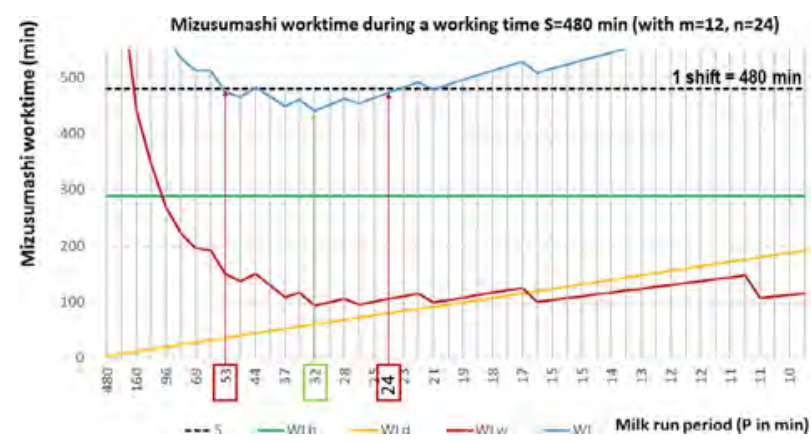

Fig. 4. Graphical analysis of the real case with large parts: work time is a function of the milk-run period ( $\mathrm{P}$ ) for a work time $\mathrm{S}$ of $480 \mathrm{~min}$ (1 shift), with 12 POUs and 24 delivery parts.

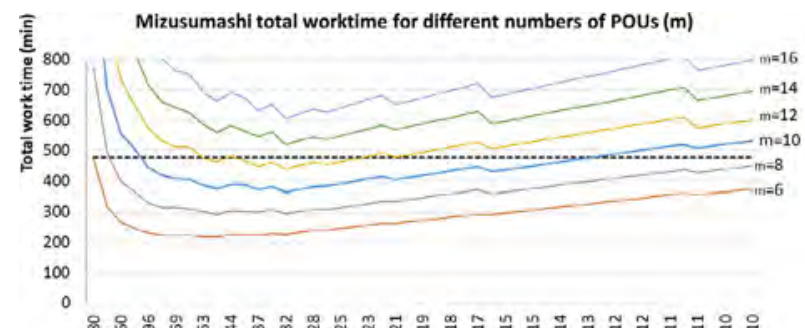

Milk run period ( $P$ in $\min$

Fig. 5. Work time versus number of POUs $\mathrm{m}$, with $n=2 \cdot \mathrm{m}$.

Figs. 4 and 5 show the results of the graphical analysis. The following main conclusions are reached for the studied case:

- Minimum $W L$ happens when $P=32$ min. By applying the continuous function approach, explained in Sub-Section 4.1 and Eq. (13), to calculate the optimal $P$, the value obtained in that case is $26.7 \mathrm{~min}$, which is very consistent with the results from the case study.

- Milk-run circuit is possible only if $53 \mathrm{~min}>P>24 \mathrm{~min}$; otherwise, the mizusumashi's total work time is higher than work time $\mathrm{S}$.

- Values of $P$ higher than the minimum make the work time increase, but smoothly. This implies that it is possible to reduce the surface (by reducing $P$ ) without too much impact on human productivity. For instance, with $m=12$ a reduction of $25 \%$ in $\mathrm{P}$ (from $32 \mathrm{~min}$ to $24 \mathrm{~min}$ ) would increase WL only by $7.2 \%$ (from 441.6 to $473.6 \mathrm{~min}$ ).

- Graphical analysis helps in assigning the number of delivery points (m) (see Fig. 5). For instance, $m=12$ is feasible, but $m=14$ is not feasible.

\section{Conclusions and future research}

This paper presents a method for a single in-plant milk-run design. It has been developed for reducing surface occupation and then achieving minimum mizusumashi work time. The "preloading method' has proven to be a requisite technique for reducing production lines surface and for precise calculation of the number of required coaches. Also, we have found that shortening the replenishment period $(P)$ is suitable for minimizing the number of containers at POUs, which in turn reduces the surface needed.

Based on observation and practice, a method for stopping and moving the milk-run train has been described to minimize mizusumashi motion and walking time.

This method models the mizusumashi's work time (WL) as a function of the replenishment period $(P)$, which allows to conclude that there is an optimum $P$ that minimizes the mizusumashi's work time.

A graphical analysis of $W L(P)$ provided some interesting additional conclusions regarding the relationships between labour and surface productivity:
- If labour productivity is the key cost driver, then supplying at the optimum $P$ allows supplying more POUs, thus reducing the total number of mizusumashis and trains needed.

- If surface productivity is the key cost driver, then milk run could be conducted with a shorter $P$ than the optimum one without too much impact on labour productivity, thus reducing the inventory of production lines.

This method is particularly useful for high-consuming surface value chains, such as supplying high volume parts to a medium or high number of POUs, which is common among industry settings nowadays.

The main limitation of this research is to consider a single milkrun design and to calculate $W L$ in a work period (typically one shift) rather than in every loop. As a consequence, variability due to traffic congestions or differences in the number of containers handled in every loop has not been considered. This limitation opens new avenues for further research, namely to:

- Calculate more precisely the coaches configuration based on the Bin Packing Problem in order to model a more accurate $W L_{w}(P)$.

- Study traffic congestion when more than one milk-run is required.

- Analyse the impact of variability in the milk-run system by means of discrete simulation tools, which can affect the handling time in every single loop.

- Understand the effect of $u$ (parts per container) in the consumption of containers per loop.

\section{References}

[1] Ohno T (1988) Toyota Production System: Beyond Large-Scale Production, Productivity PressCambridge, Massachusetts.

[2] Baudin M (2004) Lean Logistics: The Nuts and Bolts of Delivering Materials and Goods, Productivity PressNew York.

[3] Klenk E, Galka S, Günthner WA (2015) Operating Strategies for In-Plant Milk-Run Systems. IFAC Papers Online 48(3):1882-1887.

[4] Chee SL, Chong MY, Chin JF (2012) Milk-Run Kanban System for Raw Printed Circuit Board Withdrawal to Surface-Mounted Equipment. Journal of Industrial Engineering and Management 5(2):382-405.

[5] Horbal R, Kagan R, Koch T (2008) Implementing Lean Manufacturing In High-Mix Production Environment, 257, IFIP (International Federation for Information Processing), 257-267.

[6] Toyota Motor Corporation. Logistics, Production Part Logistics, Retrieved September 3 2019, from: https://www.toyota-global.com/company/history of toyota/75years/ data/automotive_business/production/logistics/production_parts/index.html.

[7] Schonberger RJ (1982) Japanese Manufacturing Techniques. Nine Hidden Lessons in Simplicity, The Free Press.

[8] Ichikawa H (2009) Simulating an Applied Model to Optimize Cell Production and Parts Supply (mizusumashi) for Laptop Assembly. In: Proceedings of the Winter Simulation Conference.

[9] Nomura J, Takakuwa S (2006) Optimization of a Number of Containers for Assembly Lines: The Fixed-Course Pick-Up System. International Journal of Simulation Modelling 5(4):155-156.

[10] Emde S, Fliedner M, Boysen N (2012) Optimally Loading Tow Trains for JIT-Supply of Mixed-Model Assembly Lines. IIE Transactions 44:121-135.

[11] Faccio M, Gamberi M, Persona A, Regattieri A, Sgarbossa F (2013) Design and Simulation of Assembly Line Feeding Systems in the Automotive Sector Using Supermarket, Kanbans and Tow Trains: A General Framework. Journal of Management Control 24(2):187-208.

[12] Emde S, Gendreau M (2017) Scheduling In-House Transport Vehicles to Feed Parts to Automotive Assembly Lines. European Journal of Operational Research 260 (1):255-267.

[13] Korytkowski P, Karkoszka R (2016) Simulation-Based Efficiency Analysis of An InPlant Milk-Run Operator Under Disturbances. International Journal of Advanced Manufacturing Technology 82:827-837.

[14] Kilic HS, Durmusoglu HS, Baskak M (2012) Classification and Modelling for InPlant Milk-Run Distribution Systems. International Journal of Advanced Manufacturing Technology 62:1135-1146.

[15] Gyulaia D, Pfeiffera A, Sobottkab T, Váncza J (2013) Milkrun Vehicle Routing Approach for Shop-floor Logistics. Procedia CIRP 7:127-132

[16] Boonprasurt P, Nanthavani S (2017) Hybrid Genetic Algorithm for Vehicle Routing Problem With Manual Unloading Consideration. Maejo International Journal of Science and Technology 11(1):68-80.

[17] Gil Vilda F, Yagüe JA, Suñé A, Jauregui-Becker JM, Wits W (2018) A Geometrical Model for Managing Surface Productivity of U-shaped Assembly Lines. CIRP Annals - Manufacturing Technology 67(1):479-482.

[18] Delorme M, Iori M, Martello S (2016) Bin Packing and Cutting Stock Problems: Mathematical Models and Exact Algorithms. European Journal of Operational Research 255(1):1-20.

[19] Khairuddin U, Razi NAZM, Abidin MSZ, Yusof R (2020) Smart Packing Simulator for 3D Packing Problem Using Genetic Algorithm. Journal of Physics: Conference Series 1447:012041. 